Da enunciação da verdade ao enunciado do gozo: o mito

Cláudio Oliveira

Professor de Filosofia da Universidade Federal Fluminense (UFF) 


\section{Da enunciação da verdade ao enunciado do gozo: o mito}

Em seu Seminário XVII, O avesso da psicanálise, há duas afirmações de Lacan sobre o mito. A primeira é a de que o mito é um saber como verdade; segunda: $o$ mito é um enunciado do impossível. Não me parece imediatamente evidente como estas duas afirmações podem ser articuladas. Tentarei, assim, chegar à segunda afirmação partindo da primeira, mas farei também o esforço de mostrar como a passagem de uma à outra é necessária, e como ela se dá ao longo do percurso de Lacan. Nesse percurso serão importantes pequenas passagens por Hegel, Platão e Heidegger. O percurso que se realiza entre as duas dimensões do mito é um percurso que vai da enunciação da verdade ao enunciado do gozo. Para que esse percurso pudesse ser feito, Lacan teve que acrescentar ao par hegeliano, saber e verdade, um terceiro elemento, o gozo - um elemento ausente nos primeiros anos de seu ensino

Palavras-chave: saber, verdade, gozo, Lacan, Hegel, Heidegger

From the enunciation of the truth to the expression of rejoice: the myth The aim of the paper is to discuss the compatibility of Lacan's propositions concerning myth posed in Séminaire XVII, as "knowledge of the truth" and as "enunciation of the impossible", so as to show that they are connected in the sense that myth is the exposition of a process that links enunciation of the truth with a state of rejoice. Elements of Hegel philosophy play an important role in this intricate arrangement.

Key words: knowledge, truth, rejoice, Lacan, Hegel, Heidegger
Sabemos com que precisão conviria acompanhar essa temática da verdade e de seu viés no saber - embora princípio, ao que nos parece,

da filosofia como tal.

Jacques Lacan, Do sujeito enfim em questão

O começo é um mito. E no começo sempre há um mito. A psicanálise não pôde evitá-lo, não mais que a filosofia. E em seu ensino, em alguns momentos, Lacan teve de tratar do mito. Destaco um desses momentos. Em seu Seminário XVII, O avesso da psicanálise, há duas afirmações de Lacan sobre o mito. A primeira é a de que o mito é um saber como verdade. A segunda é a de que o mito é um enunciado do impossível. Não me parece imediatamente evidente como essas duas afirmações podem ser articuladas. Tentarei, assim, chegar à segunda afirmação partindo da primeira, mas farei também o esforço de mostrar como a passagem de uma à outra é necessária, e como ela se dá ao longo do percurso de Lacan. Nesse percurso serão importantes pequenas passagens por Hegel, Platão e Heidegger.

A primeira afirmação lacaniana deve surpreender. Um saber como verdade é o que, a priori, deveria estar fora do ensino de Lacan, na medida em que a verdade, nesse ensino, é o que está excluído do campo do saber ou, mais precisamente, internamente excluído: o que escapa ao saber só aparece, no campo do saber, como falha do saber. Daí que, para entender a importância da afirmação de que o mito é um saber como verdade, um saber que tem função de verdade, precisamos levar em conta que, para Lacan, verdade e saber em geral se opõem. Essa oposição, Lacan a extrai da Fenomenologia do espírito 
de Hegel, do modo como Hegel dá, nessa obra, as determinações do saber e da verdade, tais como elas ocorrem na consciência.

A consciência, nos diz Hegel, distingue algo de si, o objeto, mas ao mesmo tempo se relaciona com isso. Isso quer dizer que o que a consciência distingue de si, ao mesmo tempo, é para a consciência. Esse estar relacionado com a consciência, esse ser para a consciência, Hegel o chama de saber. Só que, desse ser para a consciência, desse ser para um outro, deve-se distinguir o ser em si mesmo. Isso que se relaciona com o saber deve se distinguir dele e se pôr como algo que é, mesmo fora dessa relação. É esse lado do em si que Hegel chama de verdade, tal como a consciência a entende.

Mas Hegel não pára por aí, na medida em que, em sua história, em sua fenomenologia, a própria consciência não pára por aí. Pois se a verdade escapa ao saber, há, no entanto - e a consciência tem de reconhecê-lo - uma verdade do saber. Isso que Hegel chama de verdade do saber poderia parecer que é o mesmo que Lacan chama de saber como verdade, mas não é. O saber como verdade não é a verdade do saber. A verdade do saber, como Hegel a entende, é o que o saber é em si, na medida em que a verdade, tal como a entende a consciência, é esse em si que se opõe ao saber. Se há um em si do saber, se há o que o saber é em si, há uma verdade do saber. Ao investigar o que o saber é em si, o saber se torna objeto de si mesmo, ele é para si mesmo. O que resulta daí é que, no que diz respeito à verdade do saber, o ser em si e o ser para um outro (no caso, para a consciência) são o mesmo, na medida em que tal distinção ocorre no interior da própria consciência: a essência do saber, enquanto sua verdade, é o próprio saber, e não um objeto que ele não seja. Aqui, a verdade está no próprio saber e não fora dele. Nesse caso, ultrapassa-se a separação entre saber e verdade. É isto o que Hegel chama “consciência de si”, Selbstbewusstsein. Diz ele: "a consciência, por um lado, é consciência do objeto; por outro lado, consciência de seu si mesmo (seiner selbst): é consciência disso que, para ela, é o verdadeiro e consciência de seu saber disso" (Hegel 1, p. 77 [2002, p. 79])
Lacan, por outro lado, ao falar do saber como verdade, o distingue radicalmente do saber da verdade ou da verdade do saber que Hegel chama de Sebstbewusstsein, a consciência de si. Ao perguntar "o que é a verdade como saber?", Lacan acrescenta: “Como saber sem saber?" (Lacan 2, p. 39). O saber como verdade, para Lacan, não podemos esquecê-lo, é um saber que não se sabe. Por isso, não se trata, para Lacan, de um Sebstbewusstsein, mas de um Unbewusstsein. Não se trata, para Lacan, de Consciência de si, mas de Inconsciente; em outras palavras, Lacan não é hegeliano, mas freudiano.

Isso não o impede, é verdade, de se apropriar da dialética hegeliana entre saber e verdade para dar a ela uma outra resolução que não aquela da consciência de si. Mais precisamente, Lacan não dá à dialética do saber e da verdade nenhuma solução, mas a mantém insolúvel. O que ele quer dela é propriamente a oposição, que ela introduz, entre saber e verdade. O mito, nesse sentido, enquanto saber como verdade, também não resolve essa oposição, antes a encarna.

É o que, para Lacan, distingue o discurso mítico do discurso científico, na medida em que o discurso científico resolve a dialética entre saber e verdade simplesmente abolindo a última. Se o mito é um saber como verdade, a ciência é um saber sem verdade, um saber que já não tem nenhuma relação com a verdade e, por isso mesmo, um saber inteiramente autônomo do saber mítico. A afirmação de que a ciência é um saber sem verdade, um saber que não tem nenhuma relação com a verdade, pode surpreender, ou mesmo chocar. Heidegger também produziu um escândalo semelhante ao afirmar que "a ciência não pensa" (Heidegger 6, p. 115). No entanto, à medida que entendemos o que Lacan entende por verdade, essa surpresa e esse escândalo diminuem. A ciência não tem nenhuma relação com a verdade, na medida em que o discurso da ciência, para Lacan, só se sustenta por uma lógica que faz da verdade um jogo de valores, excluindo radicalmente aquilo que ele chama de sua potência dinâmica: 
Com efeito, o discurso da lógica proposicional é, como se sublinhou, fundamentalmente tautológico. Consiste em ordenar proposições compostas de maneira tal que elas sejam sempre verdadeiras, seja qual for, verdadeiro ou falso, o valor das proposições elementares. Não será isso se livrar do que chamava, há pouco, de dinamismo do trabalho da verdade? (Lacan 2, p. 103)

Esse dinamismo do trabalho da verdade, Lacan o tratou, no início de seu ensino, como "a função da verdade em seu estado nascente" (Lacan 3, p. 13 [1985, p. 11]). Já em seu Seminário II, ele se vê às voltas com essa "singular ambigüidade entre saber e verdade" (ibidem), que, segundo ele, se vê desde a origem, na medida em que tomemos, por exemplo, Platão como origem. É no Ménon de Platão que ele vai, de início, tentar mostrar essa inércia própria ao saber, que o faz perder algo da virtude a partir da qual ele surge e, uma vez surgido, começar a se depositar, "numa evidente propensão a desconhecer seu próprio sentido” (ibidem). O que Lacan mostra, aí, é que o saber tem uma origem, a verdade, mas que ele tende sempre a esquecer essa origem, o que quer dizer que ele tende sempre a esquecer sua verdade, como se fosse um saber sem verdade. O mito, ao contrário, trata dessa origem. O mito é sua memória. Como o inconsciente, nos termos de Freud, o mito é a memória do que o homem esquece. E é nesse sentido que o mito tem a ver com a verdade em seu estado nascente. Não esquecê-la é sua função, e é nisso que a psicanálise se aproxima do mito. Como diz Lacan, "nós analistas, que trabalhamos na dimensão desta verdade em estado nascente, não podemos esquecê-la” (Lacan 3, p. 29 [1985, p. 30]).

Toda a meta e o paradoxo do Ménon de Platão, segundo Lacan, consistem em mostrar como a epistéme, esse saber ligado por uma coerência formal, deixa escapar precisamente aquilo que constitui a virtude, a areté da experiência humana: "O que Sócrates destaca é muito exatamente o seguinte - não existe uma epistéme da virtude" (Lacan 3, p. 26 [1985, p. 26]). Péricles e Temístocles, que estão aqui enquanto modelos de homens virtuosos, agem em função não de uma epistéme, mas, como diz Sócrates, de uma ortodoxa, o que Lacan entende do seguinte modo: "existe aí um verdadeiro que não é apreensível num saber ligado" (ibidem). Se a constituição de uma epistéme é entendida, em geral, como a função de Sócrates, Lacan entende o Ménon como o lugar em que Platão deixa claro que "Sócrates não crê que isto seja tudo" (ibidem).

O Ménon nos dá mostra, segundo Lacan, de que "há em todo saber, uma vez constituído, uma dimensão de erro, que consiste em esquecer a função criadora da verdade em sua forma nascente" (Lacan 3, p. 29 [1985, p. 30]). O trabalho nessa dimensão da verdade é o que, no Seminário XVII, Lacan chama de dinâmica da verdade. $\mathrm{O}$ discurso analítico não só não pode esquecer tal dimensão, mas também se distingue por formular a pergunta de para que serve essa forma de saber, a ciência, que rejeita e exclui a dinâmica da verdade. A resposta de Lacan é: "serve para recalcar aquilo que habita o saber mítico” (Lacan 2, p. 103 [1992, p. 85]). Ao excluir a dinâmica da verdade que habita o saber mítico, a ciência, no mesmo movimento,

nada mais conhece dele a não ser sob a forma do que reencontramos nas espécies do inconsciente, quer dizer, como resíduo desse saber, sob a forma de um saber disjunto. O que será reconstruído desse saber disjunto não retornará de maneira alguma ao discurso da ciência. (...) Esse saber disjunto, tal como o reencontramos no inconsciente, é estranho ao discurso da ciência. (ibidem).

O que é esse recalcado pelo discurso da ciência que habita o saber mítico? O que é esse resíduo de saber que não pode retornar ao discurso da ciência senão como saber disjunto? O que é essa forma do saber que a psicanálise reencontra no inconsciente, nas espécies do inconsciente, esse estranho ao discurso da ciência? 
Esse estranho é o saber como verdade. Enquanto saber disjunto, o saber mítico não é senão o saber que advém no lugar da verdade, o saber como verdade. E o que é o saber como verdade? Segundo Lacan, é um saber que se sustenta como um semi-dizer e tem a forma do enigma (Lacan 2, p. 39 [1992, p. 33]). O enigma é o saber como verdade, na medida em que a própria verdade só se sustenta em um semi-dizer.

Essa idéia de que a verdade só pode ser dita pela metade, de que ela nunca pode ser dita toda, Lacan a extrai de Heidegger. Como ele mesmo diz na última lição do Seminário XVII: "Não fui eu quem inventou essa dimensão da verdade que faz com que ela esteja oculta. É a Verborgenheit que a constitui" (Lacan 2, p. 216 [1992, p. 179]). Verborgenheit é o termo alemão com o qual Heidegger pensa a essência da verdade: a essência da verdade, para Heidegger, é o velamento (Verborgenheit). Mas a essência da verdade é o velamento precisamente por Heidegger entender a verdade como desvelamento. É que toda verdade, enquanto desvelamento, enquanto deixar-ser, é, "em si mesmo, ao mesmo tempo, um velar (Verbergen)" (Heidegger 5, p. 21 [1979, p. 141]). O velamento, na medida em que se entende a verdade como desvelamento, é o não-desvelamento. E se um velar pertence essencialmente a todo desvelar, é porque a não-verdade pertence à essência da verdade. E o que se vela, em todo desvelamento? A resposta de Heidegger é que o velamento (a Verborgenheit) é o velar-se do que é no todo (Die Verbergung des Seienden im Ganze). Heidegger assim descreve esse "no todo":

Este "no todo" aparece à preocupação e ao cálculo cotidiano como o imprevisível e o inconcebível. Este "no todo" jamais se deixa captar a partir do ente que se manifestou, pertença ele quer à natureza, quer à história. Ainda que a tudo constantemente determinando, este "no todo" permanece o Indeterminado, o Indeterminável (...). Este determinante, no entanto, não é um nada, mas um velar-se do que é no todo [eine Verbergung des Seiende im Ganzen] (ibidem).
O velamento desse "no todo", essa não-verdade original, é, para Heidegger, mais antiga que toda revelação de tal ou tal ente. O velarse do velado no todo, Heidegger o chama "o Mistério", Das Geheimnis, expressão na qual ressoa o jogo freudiano heimlich-unheimlich. O que o homem tem de mais próprio é o que ele tem de mais misterioso; o que tem de mais próximo é o que tem de mais estranho. A verdade de cada um é um mistério para cada homem. Por isso, o mistério, enquanto velar-se do velado, domina, segundo Heidegger, o existir do homem.

É dessa reflexão heideggeriana em torno do simultâneo desvelamento e velamento, em jogo em toda verdade, que Lacan chega ao enunciado de que a verdade é não-toda: "O próprio da verdade é isto - a verdade, nunca se pode dizê-la a não ser pela metade" (Lacan 2, p. 39 [1992, p. 34]). Por isso, o semi-dizer é a lei interna de toda espécie de enunciação da verdade, e também por isso, o que melhor a encarna é o mito.

Lacan ilustra isso através do mito de Édipo, mas não através daquilo que, no mito, foi transformado por Freud em complexo. Lacan se refere ao fato de que, nesse mito, a Quimera propõe um enigma a Édipo, e em função da resposta que lhe dá que Édipo se torna Édipo. Aqui aparece a função do enigma, do saber como verdade, como um semi-dizer, a própria Quimera encarnando esse semi-dizer na medida em que se faz aparecer como um meio-corpo.

O mesmo mito também mostra como o saber como verdade define o que deve ser a estrutura do que se chama, em psicanálise, uma interpretação. Para entendê-la, é preciso insistir na diferença que Lacan propõe, desde o início de seu ensino, como uma diferença de nível entre a enunciação e o enunciado.

O enunciado é o que se diz, a enunciação é o que se quer dizer com o que se diz. A enunciação fica abolida no discurso científico, na medida em que, para esse discurso, não há a questão do que se quer dizer, mas apenas a questão do que se diz. No discurso científico, a questão do que se quer dizer fica abolida porque nesse discurso 
não se quer dizer nada: falta um sujeito que possa sustentar esse querer dizer. Um discurso só é propriamente científico se não quer dizer nada. Por isso, o discurso científico é um discurso constituído apenas de enunciados. Nele não há enunciações, o que é um outro modo de dizer que o discurso científico deixa de fora a questão da verdade. Pois o que insiste no enunciado, como a sua outra metade, a enunciação, é um efeito da verdade sobre o enunciado. Só um enunciado que tem relação com a verdade leva também consigo uma enunciação. $\mathrm{O}$ enunciado científico não possui nenhuma enunciação exatamente por não ter nenhuma relação com a verdade. No entanto, se, ao falar, um sujeito faz não apenas um enunciado, mas também uma enunciação, é porque a relação com a verdade já se estabeleceu e já o atravessou. Não existe enunciado da verdade, mas apenas sua enunciação.

Se Lacan introduz a distinção entre o enunciado e a enunciação, o faz, justamente para que a função do enigma ganhe sentido. $\mathrm{O}$ enigma é, para Lacan, uma enunciação, diante da qual ficamos encarregados do enunciado. Diante de uma enunciação, diante de um enigma, temos de nos virar, como fez Édipo, e depois sofrer as conseqüências. A fórmula de Lacan é: "O enigma é a enunciação - e virem-se com o enunciado” (Lacan 2, p. 40 [1992, p. 34]). É nesse sentido que o enigma, na medida em que participa do semi-dizer, é o médium sob o qual intervém a interpretação. Lacan lembra que a interpretação é com freqüência estabelecida por um enigma.

Na medida em que descreve o mito de Édipo nesses termos, Lacan muda um pouco o modo como se entende o mito e também como se entende a interpretação. Para Lacan, é a Quimera que interpreta Édipo, e não o contrário, como estamos mais acostumados a pensar. $\mathrm{Na}$ medida em que lhe lança um enigma, na medida em que lhe lança uma enunciação, é Édipo que é chamado a dar a essa enunciação um enunciado. O enunciado de Édipo cifra o enigma da Quimera e esta se dissolve em seu próprio mistério. A interpretação da Quimera consiste em dar a Édipo uma enunciação, e não um enunciado. $\mathrm{O}$ enunciado, só quem o pode dar é Édipo. O mesmo ocorre, para Lacan, numa análise. O enigma, mesmo colhido, tanto quanto possível, na trama discursiva do analisante, é um enigma no qual a enunciação é produzida pelo intérprete, isto é, o analista. Ao tratar a fala do analisante como enigma, o analista a devolve ao analisante como sua própria enunciação, diante da qual este tem de se virar. Tratar essa fala como enigma é restituir o que ela tem de enunciação: é sobretudo não considerá-la como confissão, isto é, como um enunciado sem enunciação, como um enunciado sem verdade. Não é o analista, nesse sentido, que é colocado na função de sujeito suposto saber, saber desde o qual, supostamente, interpretaria. O analista, como a Quimera, interpreta, mas quem é suposto saber é o analisante. $\mathrm{O}$ analista está ali para fazer supor um saber enquanto verdade na fala de seu paciente. A interpretação, para Lacan, tem a estrutura do saber como verdade.

É por isso que, no discurso analítico, o saber advém no lugar da verdade. Contudo, como lembra Lacan, “o que advém aí, no começo, tem um nome - é o mito” (Lacan 2, p. 126 [1992, p. 102]). É o que pode ser visto quando se trata da verdade, daquela verdade primeira, aquela que nos interessa, mesmo que a ciência renuncie a ela, mesmo que a ciência nos dê apenas seu imperativo: continua a saber. Nesse campo aberto pelo imperativo da ciência, todavia, há uma certa discordância com algo que nos concerne. E isto é ocupado pelo mito.

Essa dimensão de verdade do mito é o que tentei privilegiar aqui e, ao fazê-lo, acabei por privilegiar sua dimensão de enunciação; mas a segunda afirmação de Lacan que li, no princípio, fala do mito não como enunciação, mas como enunciado. Ela diz: o mito é "um enunciado do impossível" (Lacan 2, p. 145 [1992,. p. 118]). Como entender essa oposição que encontramos nas duas afirmações de Lacan sobre o mito?

Como enunciação, o mito se refere à verdade, mas como enunciado diz respeito ao real. Por isso, Lacan afirma que "entre nós e o real há a verdade" (Lacan 2, p. 202 [1992, p. 166]). O mito possui, por- 
tanto, uma dimensão de verdade, a do saber como verdade - pura enunciação -, mas também uma dimensão de real, a de enunciado do impossível - puro enunciado. O mito, nesse sentido, é algo que gera muitas interpretações, seu efeito de enunciação, efeito por sua vez de sua dimensão de verdade. Porém, o mito, enquanto enunciado do real, não tem nenhum sentido. O real, para Lacan, é o impossível, mas também o que não quer dizer nada. O real não tem sentido. É algo traumático. O mito é a memória desse traumático: uma memória enquanto cifra.

Essas duas dimensões do mito aparecem nisso que Lacan pensa como o nó do semi-dizer da verdade e o que dele corresponde à interpretação, e estão ligadas a isso que ele chamou de enunciação sem enunciado e enunciado com reserva de enunciação.

Tais dimensões reaparecem em suas conferências americanas, publicadas em 1975. Aí Lacan fala que a imagem do analista como alguém cujo métier consiste em se calar é um erro, um desvio. Lacan insiste na ocasião em que o analista tem coisas a dizer, mas reafirma que o que ele tem a dizer é da ordem da verdade (Lacan 4, p. 42). Lacan retoma então, mais uma vez, a questão do mito, dizendo que o que aproxima o dizer da verdade e o mito é o fato de que verdade tem uma estrutura de ficção. A verdade tem uma estrutura de ficção, segundo ele, porque passa pela linguagem e a linguagem, tem uma estrutura de ficção. Ao mesmo tempo, aproximar a verdade do mito já implica em dizer que não se pode esgotá-la, dizê-la toda. A outra metade da verdade aparece, então, como um certo impossível. O impossível de dizê-la toda é o impossível de generalizá-la, o impossível que ela valha pra todos. Trata-se de uma verdade particular. Mas o que pode particularizar uma verdade, torná-la não toda, senão o real? É nesse momento da argumentação que Lacan introduz a consideração em torno do que há de real no mito: "Digamos, que o real, também ele, pode ser mítico" (Lacan 4, p. 45). Isso não diminui a importância do mito como dizer da verdade, pois "nesta direção está o real” (ibidem).
Tudo isso é, para Lacan, profundamente inquietante. Nas suas palavras: "É profundamente inquietante que haja um real que seja mítico" (ibidem). Lacan não hesita em atribuir a esse fato, o de que haja um real mítico, a causa de que Freud tenha mantido sua doutrina da função do pai. No Seminário XVII, é também por ocasião da análise do lugar do pai no mito que Lacan forja a afirmação de que o mito é um enunciado do impossível. Trata-se, na ocasião, de demonstrar que o pai morto é o gozo e, com isso, não se está mais no nível da enunciação, mas no do enunciado, pois o que Lacan diz, na ocasião, é que "no enunciado do mito de Totem e tabu, o mito freudiano é a equivalência entre o pai morto e o gozo" (Lacan 2, p. 143 [1992, p. 116]). Ora, Lacan entende a equivalência entre pai morto e gozo como "sinal do próprio impossível" (ibidem). E se o real é o impossível, o mito como enunciado do impossível é um certo enunciado do gozo.

Assim, o percurso que se realiza aqui, entre as duas dimensões do mito, é um percurso que vai da enunciação da verdade ao enunciado do gozo. Para que esse percurso pudesse ser feito, Lacan teve que acrescentar ao par hegeliano, saber e verdade, um terceiro elemento, o gozo - um elemento ausente nos primeiros anos de seu ensino. $\mathrm{O}$ que me pergunto é se esse percurso em direção ao gozo poderia ter sido feito sem que o próprio não-todo da verdade se tivesse mostrado a Lacan a partir de Heidegger - em outras palavras, sem que uma modificação da própria noção de verdade se tivesse operado de Hegel a Heidegger, sem que Lacan tivesse se apropriado dessa modificação em seu caminho para um mais além da verdade, cujas coordenadas ele encontra em Freud. 


\section{Referências bibliográficas}

1. HEGEL, Georg. W. F. Phänomenologie des Geistes. Werke 3. Frankfurt am Main: Suhrkamp, 1998. [Fenomenologia do espírito. Petrópolis: Vozes/ Bragança Paulista: USF, 2002.]

2. LACAN, Jacques. Le Séminaire, livre XVII: L'envers de la psychanalyse. Paris Seuil, 1991. [O Seminário, livro 17: o avesso da psicanálise.Rio de Janeiro: Zahar, 1992.]

3. ___. Le Seminaire, livre II: Le moi dans la théorie de Freud et dans la technique de la psicanalyse. Paris: Seuil, 1978. [O Seminário, livro 2: o eu na teoria de Freud e na técnica da psicanálise. Rio de Janeiro: Zahar, 1985.

4. . "Conférences et entretiens dans des universités nord-americaines". In Scilicet, n. 6/7, 1975.

5. HEIDEGGER, Martin. Vom Wesen der Wahrheit. Frankfurt am Main: Vittorio Klostermann, 1997. ["Sobre a essência da verdade". In Conferências e escritos filosóficos. São Paulo: Abril Cultural, 1979 (Coleção Os Pensadores).]

6. _. . . "O que quer dizer pensar?". In Ensaios e conferências. Petrópolis: Vozes, 2002

\section{Antígona:}

heroína da psicanálise?

Phillipe van Haute

Professor da Universidade de Nijmegen, Holanda. 